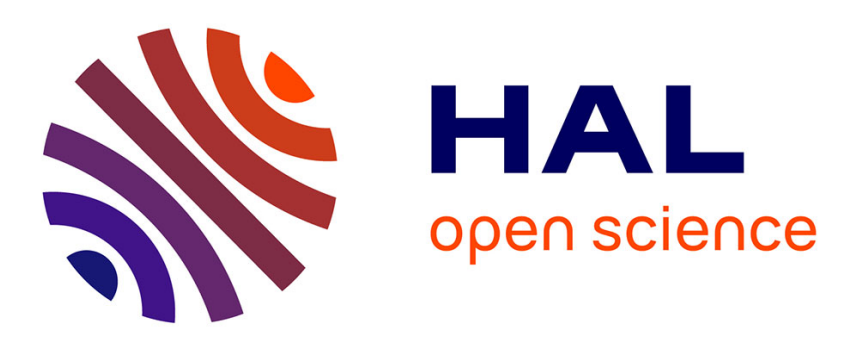

\title{
The association amongst visual, hearing, and dual sensory loss with depression and anxiety over 6 years: The Troms $\varnothing$ Study
}

S. Cosh, T. von Hanno, C. Helmer, G. Bertelsen, C. Delcourt, H. Schirmer

\section{- To cite this version:}

S. Cosh, T. von Hanno, C. Helmer, G. Bertelsen, C. Delcourt, et al.. The association amongst visual, hearing, and dual sensory loss with depression and anxiety over 6 years: The Troms $\varnothing$ Study. International Journal of Geriatric Psychiatry, 2018, 33 (4), pp.598-605. 10.1002/gps.4827 . hal01657690v2

\section{HAL Id: hal-01657690 \\ https://hal.science/hal-01657690v2}

Submitted on 27 Nov 2018

HAL is a multi-disciplinary open access archive for the deposit and dissemination of scientific research documents, whether they are published or not. The documents may come from teaching and research institutions in France or abroad, or from public or private research centers.
L'archive ouverte pluridisciplinaire HAL, est destinée au dépôt et à la diffusion de documents scientifiques de niveau recherche, publiés ou non, émanant des établissements d'enseignement et de recherche français ou étrangers, des laboratoires publics ou privés. 
Title: The association among visual, hearing and dual sensory loss with depression and anxiety over six years: The Tromsø Study

Running Head: Association of sensory loss with depression and anxiety

Authors: Cosh $\mathrm{S}^{1 ¥}$, von Hanno $\mathrm{T}^{2,3}$, Helmer $\mathrm{C}^{1}$, Bertelsen $\mathrm{G}^{4,5}$, Delcourt $\mathrm{C}^{1}$, Schirmer $\mathrm{H}^{6}$ and the SENSE-Cog Group*

${ }^{1}$ Univ. Bordeaux, Inserm, Bordeaux Population Health Research Center, team LEHA, UMR 1219, F33000 Bordeaux, France

${ }^{2}$ UiT-The Arctic University of Norway, Department of Clinical Medicine, Faculty of Health Sciences, N9037 Troms $\varnothing$, Norway

${ }^{3}$ Nordland Hospital, Department of Ophthalmology, N-8092 Bodø, Norway

${ }^{4}$ UiT The Arctic University of Norway, Department of Community Medicine, Faculty of Health Sciences, N-9037 Tromsø, Norway

${ }^{5}$ University Hospital of North Norway, Department of ophthalmology, N-9038 Tromsø, Norway

${ }^{6}$ UiT-The Arctic University of Norway, Department of Clinical Medicine, Cardiovascular research

Group-UNN, N-9037 Tromsø, Norway

${ }^{¥}$ Corresponding author

Université Bordeaux

Case 11146 rue Léo Saignat

33076 Bordeaux cedex

$\mathrm{Ph}:+33 \underline{57571393}$

Suzanne.cosh@adelaide.edu.au

Acknowledgements:

"SENSE-Cog has received funding from the European Union's Horizon 2020 research and innovation programme under grant agreement No 668648".

The Troms $\varnothing$ project has been made possible by financial support from the Research Council of Norway, North Norway Regional Health Authority and the Norwegian ExtraFoundation for Health and Rehabilitation.

Word Count : 3420

Keywords: Sensory impairment, older adults, elderly, mental health, mental wellbeing 


\section{Key Points:}

- Little is known about anxiety in sensory loss, and mental health outcomes in dual sensory loss remains unclear

- Vision loss and dual sensory loss were associated with worse depression severity over six years

- $\quad$ Hearing loss was associated with greater anxiety symptoms

- Dual loss poses a risk for greater severity of depression symptoms beyond vision loss only 
Objective: To examine the longitudinal association of dual and single (vision, hearing) sensory loss on symptoms of depression and anxiety in older adults.

Methods: 2890 adults aged 60 years or over who participated in the longitudinal population-based Tromsø Study, Norway, were included. The impact of objective vision loss, self-report hearing loss, or dual sensory loss on symptoms of depression and anxiety, as assessed by the Hopkins Symptom Checklist-10, was examined at baseline and six year follow-up using linear mixed models.

Results: Hearing loss had a cross sectional relationship with increased depression $(b=0.1750, \mathrm{SE}=0.07, p=.02)$ and anxiety symptoms $(b=0.1765, \mathrm{SE}=$ $0.08, p=.03$ ), however, these relationships were not significant at six-year follow up. Both vision loss only and dual sensory loss predicted increased depression scores at follow up ( $b=0.0220, \mathrm{SE}=0.01, p=.03 ; b=0.0413, \mathrm{SE}=0.02, p=.01$, respectively). Adjustment for social isolation did not attenuate the main depression results.

Conclusion: Dual sensory loss resulted in increased depression symptomatology over time, and posed an additional long-term risk to depression severity beyond having a single sensory loss only. Only hearing loss is associated with anxiety symptoms. Older adults with vision, hearing and dual sensory loss have different mental health profiles. Therefore, management and intervention should be tailored to the type of sensory loss. 
Sensory losses in older adults rank amongst the top 10 contributors to burden of disease in Europe ${ }^{1,2}$. Almost one-third of adults over 65 experience hearing loss $(\mathrm{HL})^{3}$ and prevalence of vision loss (VL) is around $25 \%$ in those aged over $70^{4}$. Poorer mental health has been reported in sensory $\operatorname{loss}^{5}$, having a deleterious impact on quality of life and increasing disability ${ }^{6-8}$.

To date, the majority of sensory loss and mental health literature has focused on VL and depression. Prior research consistently demonstrates that older adults with VL have an increased risk of depression ${ }^{9-13}$. Possible mechanisms include a reduction in social activities and subsequent social isolation ${ }^{14,15}$. It has also previously been demonstrated that depression and worse mental health outcomes are observed in those with poorer mobility and physical health ${ }^{16-18}$, as well as being more common amongst women ${ }^{17}$ and those who less educated, and unmarried or live alone ${ }^{19}$. Likewise, lifestyle factors such as smoking and alcohol consumption can underlie or reflect depression and poor mental health ${ }^{19}$.

A smaller body of literature indicates that there is also a cross-sectional relationship between $\mathrm{HL}$ and depression ${ }^{20,21}$; although not all studies corroborate this association ${ }^{22,23}$. One limitation of prior research is that few longitudinal studies have examined dual and single sensory loss concurrently. Depression symptoms have been reported to be more common amongst older adults with dual sensory loss (DSL) compared to single sensory loss ${ }^{24}$. Yet the three longitudinal studies to date have yielded mixed findings ${ }^{25-27}$, and it remains unclear if DSL has an additional impact on mental health over and above single sensory loss ${ }^{5}$. Thus, there remains an ongoing need to better differentiate the relative impact of single (VL or $\mathrm{HL})$ and dual sensory loss in relation to mental health, especially longitudinally $y^{5,14}$. 
Due to the previous narrow focus on depression, there remains a paucity of research examining anxiety in sensory loss ${ }^{5}$. Indeed, anxiety has been largely overlooked in the older adult literature ${ }^{16}$, despite being more prevalent than depression in community-dwelling older adults ${ }^{28,29}$. Limited cross-sectional findings indicate that $\mathrm{VL}$ is associated with increased risk of anxiety ${ }^{30-32}$. The relationship between HL and anxiety remains largely unexamined, although a small body of cross-sectional evidence indicates that older adults with $\mathrm{HL}$ are more likely to have anxiety than those without ${ }^{12,33}$. No studies to date have examined DSL and anxiety.

Currently, our understanding remains fragmented about the relative impact of VL, $H L$ and $D S L$ on mental health over time $e^{5,14}$ and anxiety remains largely unexplored in sensory loss. This study provides a longitudinal examination of the impact of DSL on anxiety and depression symptoms over six years. In addition, our study further aims to differentiate the impact of single and dual losses by concurrently assessing the longer-term impact of $\mathrm{VL}, \mathrm{HL}$, and $\mathrm{DSL}$ on mental health.

\section{Methods}

This study forms part of the SENSE-Cog multi-phase research programme, funded by European Union Horizon 2020 programme. SENSE-Cog aims to promote mental well-being in older adults with sensory and cognitive impairments (http://www.sense-cog.eu/). The first work package of this project aims to better understand the links between sensory, cognitive and mental ill-health in older Europeans. 
The Tromsø Study is a longitudinal population-based study conducted in northern Norway. The first Tromsø survey was undertaken in 1974, with an additional six surveys carried out by 2017 (occurring at approximately 6 year intervals). The study selection criteria have been a combination of total and random samples of birth cohorts of the inhabitants of Troms $\varnothing$. The survey includes postal questionnaires, and attendance at an interview and medical examination. The procedure of the Tromsø study has been outlined ${ }^{34}$. Ophthalmological assessments were first introduced in the fifth survey (Tromsø 5), and the current paper examines data from the Tromsø surveys 5 and 6 (conducted in 2001-02 and 2007-08, respectively; Tromsø 7 data are not yet available for analysis). Participants aged 60 years or older at the time of Tromsø 5 are included $(n=2890)$.

\section{Mental health outcome measures}

Depression and anxiety symptomatology were assessed using the Hopkins Symptom Checklist (HSCL)-10. This scale is derived from the HSCL-25 and has been shown to be a valid and reliable measure of psychological distress, with comparable performance to the longer version ${ }^{35}$. The Norwegian version has been validated and is widely used ${ }^{35}$. The HSCL-10 assesses both anxiety and depression symptoms. Respondents rate the severity of each symptom on a four-point scale. Four items assess anxiety and six examine depression ${ }^{36}$. In a Norwegian population both the depression and anxiety scales have been shown to correlate highly with the original version of the $\mathrm{HSCL}^{37,38}$. Anxiety scores range from four to 16 , and depression from six to 24 , with higher scores indicating greater symptom severity. HSCL was administered at baseline (Tromsø 5) and six-year follow-up (Tromsø 6). Participants missing HSCL data at either time point were excluded $(n=443)$. 


\section{Sensory loss measures}

Visual acuity was assessed using Snellen charts at a distance of 6 meters. Assessments were undertaken using participants' usual optical correction, where applicable. A Snellen score of $<20 / 30$ was classified as vision loss. Hearing loss was classified as a self-reported inability or difficulty hearing what is said in normal conversation. A further 291 participants missing sensory data were excluded.

\section{Covariate definitions}

Socio-demographic and lifestyle factors including marital status, living situation (alone, with others), level of education (elementary, secondary, higher education), smoking (past-, current- or non-smoker), alcohol consumption (less than monthly, monthly, weekly consumption), social network (self-reported having enough friends), and social activities (active involvement in 2+ clubs/associations) were collected via questionnaire $^{34}$. Medical assessments provided information regarding antidepressant use, mobility (ability to walk 10 steps unaided), Body Mass Index (BMI) (>25), selfreported health (poor, average to good), and history of stroke, diabetes, myocardial infarction, and hypertension.

\section{Statistical Analyses}

Socio-demographic and health characteristics were compared across sensory loss status using chi-square tests and one-way ANOVAs. The effects of sensory loss at baseline (Tromsø 5) on depression and anxiety symptoms at baseline and six-year follow-up were examined using linear mixed models. The baseline $\beta$ coefficient represents the association of a baseline sensory loss with baseline anxiety or 
depression score, and the $\beta$ coefficient for the anxiety/depression*time interaction represents the association of baseline sensory loss with changes in anxiety/depression score over time. VL only, HL only and DSL were concurrently examined to ascertain the relative impact of each type of sensory loss. In addition, interactions between VL and $\mathrm{HL}$ were also examined in each model, as were interactions between sensory loss with sex and education. HSCL anxiety and depression scores were log transformed due to positive skew and transformed scores were converted to z-scores for analysis.

Three models were used to examine each relationship; a model adjusting for sex and age; a second model also adjusting for education, living alone, marital status, and use of antidepressant medication; and a third model further adjusted for health and lifestyle covariates (BMI, smoking status, self-reported health, stroke, diabetes, myocardial infarction, hypertension, alcohol consumption, mobility). Sensitivity analyses were also conducted for depression outcome controlling for selfreported social isolation, a possible mechanism underlying the $\mathrm{VL}$ and depression relationship ${ }^{14,15}$. Sensitivity analyses assessed whether adjusting for social network (self-reported having enough friends) and social activities (involvement in clubs/associations) attenuated the main results. We also conducted analyses to examine a higher VL threshold (Snellen score <20/40). Results were unchanged and due to small numbers meeting this threshold, we present only the $<20 / 30$ results. Analyses were conducted using SAS 9.3 (SAS Institute, Inc., Cary, NC).

\section{Results}

Of the study sample $(n=2156)$, the majority was female $(52.9 \%)$ (Table 1$)$. Mean age was $66.9( \pm 5.2)$ years. At baseline, prevalence of single sensory loss was 
$25.2 \%(n=543)$ for vision and $13.2 \%(n=285)$ for hearing, with $6.8 \%(n=146)$

having DSL. Those with sensory losses were older and more likely to live alone, have mobility impairment and have a history of stroke, and myocardial infarction than those without sensory loss (Table 1). VL was more prevalent amongst women $(58.6 \%, n=$ 318), whereas $\mathrm{HL}$ was less common among women $(37.7 \%, \mathrm{n}=107)$.

\section{Depression symptomatology}

Severity of depression symptomatology at baseline was low (median $=7$, IQR = 6-8; HSCL range 6-24). VL did not have a cross-sectional relationship with depression symptom severity (Table 2). However, VL was associated with increased depression symptoms at six years in all models $(b=0.0220, \mathrm{SE}=0.01, p=.034) \mathrm{HL}$ was associated with increased depressive symptoms at baseline in the fully adjusted model $(b=0.1750, \mathrm{SE}=0.07, p=.019)$, yet this relationship was not significant longitudinally. For DSL, there was no cross-sectional relationship with depression, however, DSL was associated with increased depression symptomatology over time in all models $(b=0.0413, \mathrm{SE}=0.02, p=.007)$. Sensitivity analyses showed that further adjustment for social network and social activities did not attenuate the main depression results. All tested interactions were non-significant.

\section{Anxiety symptomatology}

Anxiety symptoms were also low in severity (median $=4, \mathrm{IQR}=4-5$; $\mathrm{HSCL}$ range 4-16). VL was also not significantly related to anxiety symptoms, either at baseline or after six years (Table 3). HL was associated with increased anxiety 
symptoms at baseline, even after full adjustment for covariates $(b=0.1765, \mathrm{SE}=$ $0.08, p=.026)$, however, this relationship was not significant over time. DSL was associated cross-sectionally with anxiety symptoms in the partially adjusted models, although this relationship was non-significant after full adjustment for covariates. The examined interactions were also non-significant.

\section{Discussion}

This paper offers a longitudinal analysis of depression and anxiety symptoms in older adults with sensory loss and provided the first longitudinal analysis of DSL and anxiety ${ }^{5}$. DSL was found to have a longitudinal relationship with depression, but not anxiety. Our analysis also demonstrated that VL, HL and DSL have different mental health profiles, with HL related cross-sectionally to both depression and anxiety, whereas VL and DSL have a longitudinal association with depression. DSL poses an additive depression risk longitudinally beyond that attributable to VL.

Sensory loss and depression

Consistent with previous findings ${ }^{9,10}$, VL was associated with increased depression symptoms over time, although no cross-sectional relationship was observed. Conversely, we showed that HL had a cross-sectional, but not longitudinal, association with depression. While results exploring hearing and depression have yielded mixed findings, our results build support for the previously reported crosssectional association between $\mathrm{HL}$ and depression in older adults ${ }^{20,21}$. Whether dual loss confers additional risk to mental health beyond single sensory loss also remains 
unclear, with mixed results to date $e^{14,26,39,40}$. Our findings suggested an association with depression over time, beyond that attributable to $\mathrm{VL}$ alone. This finding is consistent with McDonnall ${ }^{25}$, who showed that depression symptomatology increased at a faster rate after the onset of DSL than those without DSL, regardless of a prior single sensory loss. Conversely, two previous studies ${ }^{26,40}$ reported that those with DSL were not more likely than those with VL alone to experience depression. However, in both of those studies, depression was examined as a dichotomous variable rather than an assessment of symptom severity. Taken together, these findings suggest that DSL does not pose an additional risk beyond VL for developing depression symptoms, but rather, those with DSL experience a higher severity of depression symptoms than observed in $\mathrm{VL}$ alone. Thus our findings suggest that older adults with VL and DSL are both at long term risk of developing depression, and the population with DSL are particularly at risk of experiencing more severe depression long-term.

Possible suggested mechanisms through which VL and DSL are associated with depression include reduced social interaction, social isolation and loneliness due to the sensory loss ${ }^{14,15}$. In our sensitivity analyses, adjustment for social activities and number of friends did not attenuate depression results, suggesting that the relationship is better explained through other factors; or that these variables do not adequately capture social isolation. A reduction in activities of daily living (ADLs) has also been argued to be a mechanism through which VL and DSL are linked with depression ${ }^{9,26,41}$. Those with DSL have greater ADL limitations ${ }^{42}$, possibly underlying their risk for a greater severity of depression. Moreover, it has been argued that reduced light absorption in VL might lead to disturbed synthesis of melatonin ${ }^{43}$. Disrupted melatonin secretion substantially impacts the body's circadian rhythms, 
including sleep-wake patterns and social rhythms, which can lead to mood disturbance and depression ${ }^{44,45}$; with light therapy a well-established treatment for both Seasonal Affective Disorder and non-seasonal Major Depressive Disorder ${ }^{46}$. Reduced light absorption impeding melatonin synthesis may be particularly pertinent in our Norwegian population which already has low light exposure. Such a mechanism also better explains why VL and DSL, but not $\mathrm{HL}$ alone, have a longitudinal association with depression.

Our results also highlight that older adults with $\mathrm{HL}$ are at increased risk of depression, but that this relationship attenuates over time. Thus, in the case of $\mathrm{HL}$, there is possibly a period of adjustment, after which symptoms no longer increase. Restricted communication ${ }^{27,47}$ and associated loneliness ${ }^{23}$ may partially explain the observed cross-sectional association with depression. It is plausible that older adults with $\mathrm{HL}$ were able to adjust to their loss via modifying or improving their communication skills ${ }^{25}$ or by accessing hearing interventions and support ${ }^{48}$, thereby protecting older adults from subsequent or ongoing psychopathology. Further study of possible psychosocial adjustment to $\mathrm{HL}$ and mechanisms thereof would be a valuable focus of future research. This would facilitate a better understanding of how to support older people with sensory loss and promote adjustment, thereby minimising the adverse impact of sensory loss on mental well-being.

Sensory loss and anxiety

Building on the limited extant research exploring the association between sensory loss and anxiety, it was found that sensory loss did not have a longitudinal association with anxiety symptoms. In our study, only $\mathrm{HL}$ was related to anxiety and, 
as with depression symptoms, this relationship was only cross-sectional. Our findings are consistent with the scant research to date ${ }^{33,49}$ which also shows a cross-sectional relationship between anxiety and HL. Thus it appears that those with $\mathrm{HL}$ have a short-term increase in global psychological distress, but symptoms do not increase over time, possibly indicative of adjustment to HL. Social isolation and sensory deprivation are possible mechanisms underlying the relationship between $\mathrm{HL}$ and anxiety $^{33}$. It remains plausible that improvements made in communication skills might partially account for the change observed in psychological symptomatology over time. Conversely, anxiety is characterized by marked avoidance, with avoidance of anxiety-inducing places and situations reducing the frequency of experiencing anxiety symptoms (as measured on self-report questionnaires). It is therefore possible that those with $\mathrm{HL}$ became increasingly avoidant of anxiety-inducing situations (e.g., social situations, going out alone) and thus report less symptomatology over time, which is not captured by the HSCL.

Anxiety has a deleterious impact on quality of life, increases levels of disability ${ }^{16}$, and decreases the ability to manage one's hearing loss ${ }^{50}$, therefore, anxiety symptoms should be addressed when older adults develop HL to prevent further disability and any worsening of the sensory loss. Furthermore, patients with comorbid anxiety and depression have increased mental health symptom severity and chronicity, as well as greater functional loss and worse treatment outcomes ${ }^{51}$. The association of $\mathrm{HL}$ with both depression and anxiety suggests that comorbid depression and anxiety may be common in this population, further underscoring the need for rehabilitation and mental health service provision for HL.

DSL and anxiety have not previously been examined longitudinally ${ }^{5}$, and our study found that DSL does not pose a risk for anxiety symptoms. Although some 
studies have suggested cross-sectional relationships between anxiety and eye diseases ${ }^{52,53}$ and $\mathrm{VL}^{30-32}$, we found no such cross-sectional effect. These differing results may be due to our use of a less severe threshold for VL. Additionally, there is substantial heterogeneity in anxiety measures used across studies. The HSCL measures general anxiety and some symptoms of panic, but does not measure avoidance and social anxiety; both of which might be more strongly linked with sensory loss. The anxiety and sensory loss literature remains scant but has predominantly examined only a broad range of anxiety symptoms rather than undertaking anxiety disorder-specific examinations. Anxiety disorders are heterogeneous with different etiologies and may be differentially related to aspects of physical health. Prevalence rates differ for specific anxiety disorders amongst those with $\mathrm{VL}^{31}$, with agoraphobia and social phobia being the most common. It is likely that single and dual sensory loss would have differential relationships with varying anxiety disorders; which necessitate specific and targeted treatment and intervention. Ongoing research examining disorder-specific relationships with sensory loss will be invaluable for providing a clearer and more comprehensive picture of the mental health needs of older adults.

In contributing to understanding of the interplay between sensory loss and mental well-being, this paper provides a strong rationale for improving health services and interventions to better meet to the mental health needs of older adults with sensory loss(es). An increased focus on optimising aids and corrections is needed, given that use of assistive aids has been shown to reduce depression and mental health burden ${ }^{47,54,55}$. This is particularly important given the high rate of correctable $\mathrm{VL}$ in older populations ${ }^{56}$. Furthermore, older adults with VL and DSL, particularly, would benefit from depression intervention, whilst those with $\mathrm{HL}$ appear to have an 
immediate need for support regarding both depression and anxiety. Treatment of depression in those with VL is especially critical given the bidirectional nature of the VL-depression relationship ${ }^{9}$. Interventions might also aim to facilitate acceptance of the loss(es), which has been shown to lead to adjustment and reduced depression over time ${ }^{25,57}$. It is particularly pertinent that services are directed towards older adults with sensory loss, given that over one third of older adults with VL and comorbid mental disorders do not receive mental health services ${ }^{58}$.

\section{Strengths and Limitations}

This study is presented with several strengths including concurrent examination of DSL and single sensory loss. A further strength is that both anxiety and depression symptoms were explored, allowing for a better insight into the mental health profiles of sensory loss in older people. However, this study has some limitations. Firstly, the mean age is relatively young (66.9 years) and thus may not adequately reflect functioning in the very old. Although we have undertaken one of the only longitudinal analyses of anxiety in sensory loss, there is only one follow up time point, thus we can draw limited conclusions regarding the evolution of longerterm psychological symptoms. Moreover, the study relies on self-reported hearing, which can have differential associations with mental health than measured hearing ${ }^{21}$. Due to study requirements that participants attend a clinic visit, there are few participants meeting severe VL thresholds; thus we are unable to establish the relationship between severe VL and mental wellbeing. Finally, anxiety was assessed by four non disorder-specific items. A more comprehensive assessment of anxiety would be of benefit for future research. 


\section{Conclusion}

This study provides the first longitudinal examination of depression and anxiety symptoms for concurrent sensory loss. HL has a unique relationship with anxiety symptoms and DSL poses an additional long-term risk to depression severity beyond single sensory loss. An ongoing focus on improving service provision in order to enhance uptake of targeted mental health interventions may help to reduce the burden of disease attributable to sensory loss and mental ill-health in the elderly population. 


\section{References}

1. Wittchen HU, Jacobi F, Rehm J, et al. The size and burden of mental disorders and other disorders of the brain in Europe 2010. Eur. Neuropsychopharmacol. 2011;21(9):655-679. doi:10.1016/j.euroneuro.2011.07.018.

2. Mathers $\mathrm{CD}$, Loncar D. Projections of global mortality and burden of disease from 2002 to 2030. PLoS Med. 2006;3(11):e442. doi:10.1371/journal.pmed.0030442.

3. WHO. Depression and Other Common Mental Disorders: Global Health Estimates.; 2017.

4. Stevens G, White R, Flaxman S. Global prevalence of vision impairment and blindness: magnitude and temporal trends, 1990-2010. Ophthalmology 2013;120:2377-2384.

5. Heine C, Browning CJ. Mental health and dual sensory loss in older adults: a systematic review. Front. Aging Neurosci. 2014;6:1-9. doi:10.3389/fnagi.2014.00083.

6. Hernandez Trillo AH, Dickinson CM. The Impact of Visual and Nonvisual Factors on Quality of Life and Adaptation in Adults with Visual Impairment. Investig. Opthamology Vis. Sci. 2012;53(7):4234-4241. doi:10.1167/iovs.129580.

7. Yokoi T, Moriyama M, Hayashi K, et al. Predictive factors for comorbid psychiatric disorders and their impact on vision-related quality of life in patients with high myopia. Int Opthalmology 2014;34:171-183. doi:10.1007/s10792-0139805-8.

8. Eisele M, Kaduszkiewicz H, König HH, et al. Determinants of health-related quality of life in older primary care patients: results of the longitudinal observational AgeCoDe Study. Br. J. Gen. Pract. 2015;65(640):716-23.

9. Carrière I, Delcourt C, Daien V, et al. A prospective study of the bi-directional association between vision loss and depression in the elderly. J. Affect. Disord. 2013;151:164-170. doi:10.1016/j.jad.2013.05.071.

10. Hong T, Mitchell P, Burlutsky G, Gopinath B, Liew G, Wang JJ. Visual impairment and depressive symptoms in an older Australian cohort: longitudinal findings from the Blue Mountains Eye Study. Br. J. Opthalmology 2015;99:1017-1021. doi:10.1136/bjophthalmol-2014-306308.

11. Garin N, Olaya B, Lara E, et al. Visual impairment and multimorbidity in a representative sample of the Spanish population. BMC Public Health 2014;14:815.

12. Bernabei $\mathrm{V}$, Morini $\mathrm{V}$, Moretti $\mathrm{F}$, et al. Vision and hearing impairments are associated with depressive - anxiety syndrome in Italian elderly. Aging Ment. Heal. 2011;15(4):467-474. doi:10.1080/13607863.2011.562483.

13. Ribeiro MVMR, Hasten-Reiter HN, Ribeiro EAN, Juca MJ, Barbosa FT, de Sousa-Rodrigues CF. Association between visual impairment and depression 
in the elderly : a systematic review. Arq Bras Oftalmol 2015;78(3):197-201.

14. Schneider JM, Gopinath B, Mcmahon CM, Leeder SR, Mitchell P, Wang JJ. Dual Sensory Impairment in Older Age. J. Aging Health 2011;23(8):1309-1324. doi:10.1177/0898264311408418.

15. Bookwala J, Lawson B. Poor Vision, Functioning, and Depressive Symptoms: A Test of the Activity Restriction Model. Gerontologist 2011;51(6):798-808. doi:10.1093/geront/gnr051.

16. Byrne GJ, Pachana NA. Anxiety and depression in the elderly: do we know any more? Curr. Opin. Psychiatry 2010;23:504-509. doi:10.1097/YCO.0b013e32833f305f.

17. Mehta K, Simonsick E, Penninx BWJH. Prevalence and correlates of anxiety symptoms in well-functioning older adults: findings from the health aging and body composition study. J. Am. Geriatr. Soc. 2003;51:499-504.

18. Blazer DG. Depression in Late Life: Review and Commentary. J. Gerontol. 2003;58(3):249-265.

19. Vink D, Aartsen MJ, Schoevers RA. Risk factors for anxiety and depression in the elderly: A review. J. Affect. Disord. 2008;106(1-2):29-44. doi:10.1016/j.jad.2007.06.005.

20. Gopinath B, Wang JJ, Schneider J, et al. Depressive Symptoms in Older Adults with Hearing Impairments: The Blues Mountaints Study. J. Am. Geriatr. Soc. 2009;57(7):1306-1308.

21. Lee AT, Tong MC, Yuen KC, Tang PS, Vanhasselt CA. Hearing impairment and depressive symptoms in an older chinese population. J. Otolaryngol. Head Neck Surg. 2010;39(5):498-503.

22. Mener DJ, Betz J, Genther DJ, Chen D, Lin FR. Hearing Loss and Depression in Older Adults. J. Am. Geriatr. Soc. 2014;61(9):1627-1629. doi:10.1111/jgs.12429.Hearing.

23. Pronk M, Deeg DJH, Smits C, et al. Prospective effects of hearing status on loneliness and depression in older persons: identification of subgroups. Int. J. Audiol. 2011;50(12):887-96.

24. Lupsakko T, Mantyjarvi M, Kautianien H, Silkava R. Combined hearing and visual impairment and depression in a population aged 75 years and older. Int J Geriatr Psychiatry 2002;17:808-13.

25. Capella-Mcdonnall ME. The Effects of Developing a Dual Sensory Loss on Depression in Older Adults: A Longitudinal Study. J. Aging Health 2009;21(8):1179-1199. doi:10.1177/0898264309350077. The.

26. Chou K. Combined effect of vision and hearing impairment on depression in older adults : Evidence from the English Longitudinal Study of Ageing. J. Affect. Disord. 2008;106:191-196. doi:10.1016/j.jad.2007.05.028.

27. Kiely KM, Anstey KJ, Luszcz MA. Dual sensory loss and depressive symptoms: 
the importance of hearing, daily functioning, and activity engagement. Front. Aging Neurosci. 2013;7:1-13. doi:10.3389/fnhum.2013.00837.

28. Ritchie K, Artero S, Beluche I, et al. Prevalence of DSM-IV psychiatric disorder in the French elderly population. Br. J. Psychiatry 2004;184:147-152.

29. Kvaal K, Macijauskiene J, Engedal K, Laake K. High prevalence of anxiety symptoms in hospitalized geriatric patients. Int J Geriatr Psychiatry 2001;16:690-3.

30. Kempen GI, Zijlstra GA. Clinically relevant symptoms of anxiety and depression in low-vision community-living older adults. Am J Geriatr Psychiatry 2014;22:309-13.

31. Van der Aa HP, Comijs HC, Pennix BW, Van Rens GH, Van Nispen RM. Major depressive and anxiety disorders in visually impaired older adults. Invest Ophthalmol Vis Sci 2015;56:849-54.

32. Court H, McLean G, Guthrie B, Mercer SW, Smith DJ. Visual impairment is associated with physical and mental comorbidities in older adults: a crosssectional study. BMC Med. 2014;12:181. doi:10.1186/s12916-014-0181-7.

33. Contrera KJ, Betz J, Deal J, et al. Association of Hearing Impairment and Anxiety in Older Adults. J. Aging Health 2016.

doi:10.1177/0898264316634571.

34. Jacobsen BK, Eggen AE, Mathiesen EB, Wilsgaard T, Njølstad I. Cohort profile: The Tromsø study. Int. J. Epidemiol. 2012;41(4):961-967. doi:10.1093/ije/dyr049.

35. Strand BH, Dalgard OS, Tambs K, Rognerud M. Measuring the mental health status of the Norwegian population: a comparison of the instruments SCL-25, SCL-10, SCL-5 and MHI-5 (SF-36). Nord J Psychiatry 2003;57:113-8.

36. Sogaard AJ, Bjelland I, Tell GS, Roysamb E. A comparison of the CONOR Mental Health Index to the HSCL-10 and HADS: Measuring mental health status in The Oslo Health Study and the Mord-Trondelag Health Study. Nor. Epidimiology 2003;13(2):279-284.

37. Tambs K, Moum T. How well can a few questionnaire items indicate anxiety and depression? Acta Psychiatr. Scand. 1993;87:364-367.

38. Tambs K. Moderate Effects of Hearing Loss on Mental Health and Subjective Well-Being : Results From the Nord-Trøndelag Hearing Loss Study. Psychosom. Med. 2004;66:776-782. doi:10.1097/01.psy.0000133328.03596.fb.

39. Armstrong TW, Surya S, Elliott TR, Brossart DF, Burdine JN. Depression and Health-Related Quality of Life Among Persons With Sensory Disabilities in a Health Professional Shortage Area. Rehabilition Psychol. 2016;61(3):240-250.

40. Capella-Mcdonnall ME. The effects of single and dual sensory loss on symptoms of depression in the elderly. Int. J. Geriatr. Psychiatry 2005;20:855861. 
41. Evans JR, Fletcher AE, Worwald RP. Depression and anxiety in visually impaired older people. Ophthalmology 2007;114:283-8.

42. Brennan M, Horowitz A, Su YP. Dual sensory loss and its impact on everyday competence. Gerontologist 2005;45(3):337-346.

43. Tosini G, Baba K, Hwang CK, Luvone PM. Melatonin: An unappreciated player in retinal physiology and pathophysiology. Exp. Eye Res. 2012;103:82-89. doi:10.1016/j.exer.2012.08.009.Melatonin.

44. Lieverse R, Van Someren EJ, Nielen MM, Uitdehaag BM, Smit JH, Hoogendijk WJ. Bright light treatment in elderly patients with nonseasonal major depressive disorder: a randomized placebo-controlled trial. Arch Gen Psychiatry 2011;68:61-70.

45. Even C, Schroder CM, Friedman S, Rouillon F. Efficacy of light therapy in nonseasonal depression: a systematic review. J Affect Disord 2008;108:11-23.

46. Golden RN, Gaynes BN, Ekstrom RD, et al. The efficacy of light therapy in the treatment of mood disorders: a review and meta-analysis of the evidence. $A m \mathrm{~J}$ Psychiatry 2005;162:656-62.

47. McDonnall MC. Risk factors for depression among older adults with dual sensory loss. Aging Ment. Heal. 2009;13(4):569-76.

48. Acar B, Yurkeli MF, Babademez MA, Karabulut H, Karasen RM. Effects of hearing aids on cognitive functions and depressive signs in elderly people. Arch Gerontol Geriatr 2011;52:250-2.

49. Ciesla K, Lewandowska M, Skar H. Health-related quality of life and mental distress in patients with partial deafness : preliminary findings. Eur. Arch. Otorhinolaryngol 2016;273:767-776. doi:10.1007/s00405-015-3713-7.

50. Hogan A, O'Loughlin K, Miller P, Kendig H. The Health Impact of a Hearing Disability on Older People in Australia. J. Aging Health 2009;21(8):1098-1111. doi:10.1177/0898264309347821.

51. Pennix BW. Depression and anxiety: their insidious dance. Lancet Psychiatry 2015;2:479-80.

52. Eramudugolla R, Wood J, Anstey KJ. Co-morbidity of depression and anxiety in common age-related eye diseases: a population-based study of 662 adults. Front. Aging Neurosci. 2013;5:56. doi:10.3389/fnagi.2013.00056.

53. Lim NC, Fan CH, Yong MK, Wong EP, Yip LW. Assessment of Depression, Anxiety, and Quality of Life in Singaporean Patients With Glaucoma. J Glaucoma 2016;25(7):605-12.

54. Owsley C, JR. M, Scilley K, Meek GC, Seker D, Dyer A. Effect of refractive error correction on health-related quality of life and depression in older nursing home residents. Arch. Ophthalmol. 2007;125:1471-1477.

55. Mener DJ, Betz J, Genther DJ, Chen D, Lin FR. Hearing loss and depression in older adults. J Am Geriatr Soc 2013;61:1627-9. 
56. Taylor HR, Peszullo ML, Nesbitt SJ, Keeffe JE. Costs of interventions for visual impairment. Am. J. Ophthalmol. 2007;143:561-565.

57. Senra H, Barbosa F, Ferriera P, et al. Psychologic adjustment to irreversible vision loss in adults: a systematic review. Ophthalmology 2015;122:851-61.

58. van der Aa HPA, Hoeben M, Rainey L, van Rens GHMB, Vreeken HiL, van Nispen RMA. Why visually impaired older adults often do not receive mental health services: the patient' s perspective. Qual. Life Res. 2015;24:969-978. doi:10.1007/s11136-014-0835-0. 
Table 1: Baseline characteristics by sensory loss (wave 5)

\begin{tabular}{|c|c|c|c|c|c|}
\hline & $\begin{array}{l}\text { No loss } \\
(n=1182)\end{array}$ & $\begin{array}{l}\text { Vision Loss } \\
(n=543)\end{array}$ & $\begin{array}{l}\text { Hearing Loss } \\
(n=285)\end{array}$ & $\begin{array}{l}\text { Dual Sensory } \\
\text { Loss }(n=146)\end{array}$ & $\mathbf{p}$ \\
\hline Female \% & 52.41 & 58.60 & 37.66 & 55.73 & $<.001$ \\
\hline HSCL anxiety (range 4-16) & $4.71(1.24)$ & $4.80(1.29)$ & $4.89(1.28)$ & $4.96(1.33)$ & $.052^{¥}$ \\
\hline Low education ( $0-7$ years) $\%$ & 27.88 & 36.08 & 36.24 & 53.54 & $<.001$ \\
\hline Mid education (8-13 years) \% & 55.51 & 51.55 & 54.36 & 40.94 & .009 \\
\hline Married/de facto & 73.09 & 66.00 & 68.83 & 59.54 & .004 \\
\hline BMI over 25 & 67.91 & 64.39 & 66.88 & 62.60 & .351 \\
\hline Current smoker & 20.91 & 23.74 & 11.76 & 17.56 & .011 \\
\hline Past smoker & 43.83 & 38.43 & 61.44 & 55.73 & $<.001$ \\
\hline Anti-depressant use & 1.63 & 1.39 & 2.92 & 1.68 & $.006^{\dagger}$ \\
\hline Myocardial infarction & 6.56 & 8.43 & 12.42 & 9.38 & .033 \\
\hline Stroke & 2.44 & 3.65 & 3.92 & 6.35 & $.046^{\dagger}$ \\
\hline Diabetes & 3.52 & 4.85 & 3.92 & 1.56 & .304 \\
\hline Poor mobility & 10.53 & 14.81 & 22.07 & 23.58 & $<.001$ \\
\hline Hypertension (treated) & 23.24 & 26.32 & 30.00 & 27.69 & .142 \\
\hline Social network (Enough friends) & 93.21 & 92.37 & 91.49 & 95.37 & .613 \\
\hline Activities (Participates in $2+$ social clubs) & 37.66 & 39.50 & 52.35 & 43.80 & .004 \\
\hline
\end{tabular}

${ }^{¥}$ One-way ANOVA; ${ }^{\dagger}$ Fisher's exact test; All other analyses = chi square tests.

VL vision loss; HL hearing loss; DSL dual sensory loss; HSCL Hopkins Symptom Checklist 
Table 2: Association between baseline sensory loss and depression symptoms

\begin{tabular}{|c|c|c|c|c|c|c|c|c|c|c|c|c|}
\hline & \multicolumn{3}{|c|}{ Model 1} & \multicolumn{3}{|c|}{ Model 2} & \multicolumn{3}{|c|}{ Model 3} & \multicolumn{3}{|c|}{ Sensitivity Analysis } \\
\hline & b & SE & $p$ & $\mathbf{b}$ & SE & $\mathbf{p}$ & $\mathbf{b}$ & SE & $\mathbf{p}$ & $\mathbf{b}$ & SE & p \\
\hline \multicolumn{13}{|l|}{ Vision Loss alone } \\
\hline Baseline score & -0.0055 & 0.066 & .933 & -0.0381 & 0.070 & .587 & -0.0906 & 0.071 & .200 & -0.0945 & 0.072 & .188 \\
\hline Six year score & 0.0216 & 0.009 & .017 & 0.0241 & 0.010 & .014 & 0.0220 & 0.010 & .034 & 0.0233 & 0.011 & .030 \\
\hline \multicolumn{13}{|c|}{ Hearing Loss alone } \\
\hline Baseline score & 0.2544 & 0.070 & $<.001$ & 0.2264 & 0.073 & .002 & 0.1750 & 0.074 & .019 & 0.2071 & 0.077 & .007 \\
\hline Six year score & 0.0085 & 0.010 & .396 & 0.0068 & 0.011 & .523 & 0.0022 & 0.011 & .844 & 0.0028 & 0.011 & .804 \\
\hline \multicolumn{13}{|l|}{ Dual Loss } \\
\hline Baseline score & 0.0449 & 0.120 & .708 & 0.0089 & 0.098 & .928 & -0.1144 & 0.105 & .275 & -0.0852 & 0.109 & .436 \\
\hline Six year score & 0.0499 & 0.017 & .004 & 0.0487 & 0.014 & $<.001$ & 0.0413 & 0.015 & .007 & 0.0478 & 0.016 & .003 \\
\hline
\end{tabular}

Model 1: $\mathrm{n}=2064$; adjusted for age and sex

Model 2: $n=1829$; adjusted for age, sex, education, living alone, marital status, and use of antidepressant medication

Model 3: $n=1784$; adjusted for age, sex, education, living alone, marital status, use of antidepressant medication, BMI, smoking status, self-reported health, stroke, diabetes, myocardial infarction, hypertension, alcohol consumption, mobility

Sensitivity analysis: $n=1549$, adjusted for age, sex, education, living alone, marital status, use of antidepressant medication, BMI, smoking status, self-reported health, stroke, diabetes, myocardial infarction, hypertension, alcohol consumption, mobility, social network, social activities 
Table 3: Association between baseline sensory loss and anxiety symptoms

\begin{tabular}{|c|c|c|c|c|c|c|c|c|c|}
\hline & \multicolumn{3}{|c|}{ Model 1} & \multicolumn{3}{|c|}{ Model 2} & \multicolumn{3}{|c|}{ Model 3} \\
\hline & $\mathbf{b}$ & SE & p & $\mathbf{b}$ & SE & p & $\mathbf{b}$ & SE & $p$ \\
\hline \multicolumn{10}{|l|}{ Vision Loss alone } \\
\hline Baseline score & 0.0631 & 0.066 & .338 & 0.0788 & 0.069 & .255 & -0.0149 & 0.070 & .832 \\
\hline Six year score & 0.0041 & 0.010 & .680 & -0.0013 & 0.011 & .907 & -0.0013 & 0.011 & .910 \\
\hline \multicolumn{10}{|c|}{ Hearing Loss alone } \\
\hline Baseline score & 0.3112 & 0.074 & $<.001$ & 0.2648 & 0.077 & .001 & 0.1765 & 0.079 & .026 \\
\hline Six year score & 0.0078 & 0.012 & .507 & 0.0080 & 0.013 & .522 & 0.0163 & 0.013 & .224 \\
\hline \multicolumn{10}{|l|}{ Dual Loss } \\
\hline Baseline score & 0.3082 & 0.120 & .010 & 0.2165 & 0.098 & .028 & 0.0384 & 0.106 & .717 \\
\hline Six year score & 0.0245 & 0.019 & .198 & 0.0200 & 0.016 & .187 & 0.0286 & 0.017 & .091 \\
\hline
\end{tabular}

Model 1: $\mathrm{n}=2064$; adjusted for age and sex

Model 2: $n=1829$; adjusted for age, sex, education, living alone, marital status, and use of antidepressant medication

Model 3: $n=1784$; adjusted for age, sex, education, living alone, marital status, use of antidepressant medication, BMI, smoking status, self-reported health, stroke, diabetes, myocardial infarction, hypertension, alcohol consumption, mobility 


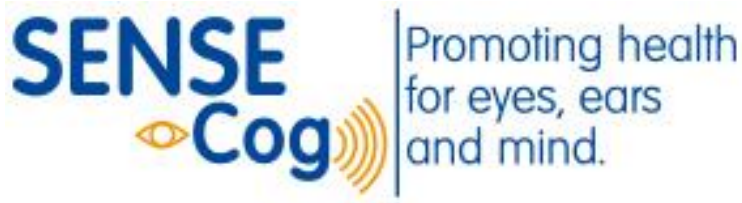

\section{${ }^{*}$ Authorlist for Sense-Cog WP1 group}

Geir Bertelsen ${ }^{1,2}$, Suzanne Cosh $^{3}$, Audrey Cougnard-Grégoire ${ }^{3}$, Piers Dawes ${ }^{4}$, Cécile Delcourt ${ }^{3}$, Fofi Constantinidou $^{5}$, Catherine Helmer ${ }^{3}$, M. Arfan Ikram ${ }^{6,7}$, Caroline CW Klaver ${ }^{6,8}$, Iracema Leroi ${ }^{9}$, Asri Maharani ${ }^{9,10}$, Magda Meester-Smor ${ }^{6,8}$, Unal Mutlu ${ }^{6,8}$, Virginie Nael ${ }^{3,11,12}$, Neil Pendleton ${ }^{9,10}$, Henrik Schirmer ${ }^{13}$, Gindo Tampubolon ${ }^{14}$, Henning Tiemeier ${ }^{6,15}$, Therese von Hanno ${ }^{16,17}$.

1: UiT The Arctic University of Norway, Department of Community Medicine, Faculty of Health Sciences, N-9037 Tromsø, Norway

2: University Hospital of North Norway, Department of ophthalmology, N-9038 Tromsø, Norway

3: Univ. Bordeaux, Inserm, Bordeaux Population Health Research Center, team LEHA, UMR 1219, F33000 Bordeaux, France

4: University of Manchester, Manchester Centre for Audiology and Deafness, School of Health Sciences, Manchester, UK

5: University of Cyprus, Department of Psychology \& Center for Applied Neuroscience, Nicosia, Cyprus

6: Erasmus Medical Centre, Department of Epidemiology, Rotterdam, The Netherlands

7: Erasmus Medical Centre, Departments of Neurology and Radiology, Rotterdam, The Netherlands

8: Erasmus Medical Centre, Department of Ophthalmology, Rotterdam, The Netherlands

9: University of Manchester, Division of Neuroscience and Experimental Psychology, School of Biological Sciences, Manchester, UK

10: University of Manchester, Academic Health Science Centre, Manchester, UK

11: Sorbonne University, UMPC University of Paris 06, INSERM, CNRS, Vision Institute, F-75012 Paris, France

12: R\&D Life and Vision Science, Essilor International, F-75012 Paris, France

13: UiT-The Arctic University of Norway, Department of Clinical Medicine, Cardiovascular research Group-UNN, N-9037 Tromsø, Norway

14: University of Manchester, Global Development Institute, Manchester, UK 
15: Erasmus Medical Centre, Department of Psychiatry, Rotterdam, The Netherlands

16: UiT-The Arctic University of Norway, Department of Clinical Medicine, Faculty of Health Sciences, N-9037 Tromsø, Norway

17: Nordland Hospital, Department of Ophthalmology, N-8092 Bodø, Norway 